\title{
CAPÍTULO III \\ Ciencias sociales, investigación y construcciones de paz: \\ Las paces en sentido epistemológico, las paces en sentido ético
}

\author{
Hernán Rodríguez Vargas ${ }^{1}$
}

\footnotetext{
1 Docente investigador colombiano. Profesional en Estudios literarios, Filósofo y Magíster en Historia. Actualmente doctorando en Historia de la facultad de Lingue, Letteratura e Storia de la UniversitàdegliStudi di Salerno (Italia). hernanvargas08@hotmail.com
} 


\title{
RESUMEN
}

En el marco de lo que significa actualmente construir distintos conocimientos sobre los social en Colombia, es necesario abordar dichos conocimientos desde el trabajo con y desde las organizaciones sociales que trabajan por la paz; ya que son ellas, quienes en medio de contextos homogenizadores y homogenizantes, invitan y abren el conocimiento que tienen las Ciencias Sociales acerca tanto de su quehacer, aquello que saben, como de qué es y cómo se configura lo social. La tesis de este texto es que entre mayor sea el interés epistemológico de las Ciencias Sociales por abrir sus horizontes investigativos en el trabajo conjunto con las diversas formas de organización social, mayores y diversas serán las formas de conocimiento que, a su vez, aúnan fuerzas para configurar modos plurales de hacer y vivir la paz, o como acá se insiste, de hacer y vivir las paces en el sentido ético del buen vivir.

Palabras clave: Ciencias Sociales, Investigación, Conocimiento, Buen Vivir.

\begin{abstract}
In the currently framework of building different knowledge about the social in Colombia, it is necessary addressing these knowledge with and from working with social organizations, which ensure for peace. This is because those, in the midst of homogenizing and homogeneous contexts, invite and open the knowledge that the Social Sciences have about their task, those things that they know, such as: what and how the social is established. The main thesis of this text is if there is an epistemological interest from the Social Sciences for opening their research horizons on the different social organization's work, the ways of knowledge will be greater and varying. As well as, those will join forces to configure plural ways for doing and living in peace or, as the article stresses, of doing and living the Peace in the ethic sense of good living.
\end{abstract}

Key words: Social Sciences, Research, Knowledge, Good living. 


\section{Introducción}

El presente texto, cuyo argumento principal es la relación entre la investigación en ciencias sociales y la construcción de paz por parte de las diferentes organizaciones, en su mayoría de víctimas ${ }^{1}$, se puede abrir con un breve relato. Hace algunos años un hombre del campo cuya sabiduría estaba puesta en la tierra y de sus frutos en los platanales, el tomate y el café, como todos los días de mercado, debía ir a la plaza a comprar, vender y cambiar aquello que recogía de la tierra. Un lunes en particular, cuando había vuelto a casa, en la vereda San José de Machetá, en Cundinamarca, se dio cuenta que alguien había dejado abandonado un reloj en su canasta. Ya era muy tarde para preguntar a quién pertenecía y no tenía sentido preguntarlo al siguiente lunes, porque lo podría reclamar cualquiera, menos su legítimo dueño. Así que decidió quedárselo sin más, aunque no supiera leer la hora así, como lo hacía la gente de la ciudad. De modo que cada vez que alguien le preguntaba "Don Valeriano, ¿qué horas tiene?”, miraba primero la posición del sol en las piedras o sobre las montañas, luego miraba el reloj con firmeza, veía a su interlocutor a los ojos y decía exactamente la hora. Este hombre sabía leer la posición del sol en el día y de las estrellas en la noche, a su tiempo y a su ritmo, pero era más importante -hablando en un sentido social- leer la hora en el reloj, antes que cualquier otra cosa; este hombre había privilegiado, sin darse cuenta, un saber sobre otro.

En este sentido se puede extender este ejemplo y decir que desde hace tiempo hemos privilegiado unas formas de ser, hacer y saber sobre otras; el conocimiento ha sido estratificado, lo cual quiere decir que hace parte de modos sociales de vida específicos. En buena medida las instituciones educativas y en especial las universidades han sido cómplices de ello. Esto no exime a las Ciencias Sociales, pero sí les da una posición privilegiada sobre el asunto, y dicha posición legitima su derecho de poder cambiar las cosas.

La tesis de este texto, que puede leerse perfectamente en clave de paz, es la

1 En el segundo apartado del texto veremos cómo esta categoría no es estática, sino más bien dinámica. 
siguiente: una de las maneras más importantes de construir paz, es lo que podríamos denominar como una paz epistemológica en la que se cambien formas de saber verticales, por formas de saber horizontales y ello nos lleve, justamente, a la construcción de una buena vida o de un buen vivir, en sentido ético. Para esto se trabajará en dos puntos centrales: 1) Investigar hoy en Ciencias Sociales, 2) Saber hacer las paces: oportunidades para abrir los conocimientos sobre lo social.

\section{Investigar hoy en Ciencias Sociales}

En el caso del hombre del ejemplo, al privilegiar un saber sobre otro, negó su propio saber, su propia existencia y afirmó otra, una aparentemente más legítima. El punto más que indicar qué es preferible, si los saberes donde se da con la hora midiendo la posición del sol en la sombra que proyecta sobre los objetos, o leer de forma correcta cómo las manecillas del reloj apuntan a un lugar u otro que une el tiempo circularmente de la 1 a las 12 , consiste en ver que son formas distintas de conocimiento, antes que antagónicas. Esto, para el caso sencillo de la situación del hombre de la historia; pero existen formas mucho más fuertes de evidenciar esta jerarquización de los saberes (Castro Gómez, 1998) y que se manifiesta cuando examinamos un currículo general de estudios universitarios.

Esto se puede hacer visible con otro ejemplo. La gran mayoría de universidades han adoptado una política del bilingüismo, donde, los estudiantes no se pueden graduar si no saben además de la lengua materna otra lengua, en general y preferiblemente, el inglés. Esto quiere decir que, como ha sucedido en varias ocasiones, un joven indígena que estudie una carrera en español, siendo su lengua originaria alguna de las lenguas nativas de Colombia ${ }^{2}$, o sea, siendo ya bilingüe, además deba por obligación aprender otra lengua, cuando, incluso

2 Acá una clasificación de las lenguas indígenas de Colombia:: http://www.banrepcultural.org/blaavirtual/antropologia/lengua/clas00.htm 
-y esta es la gran contradicción- la suya originaria no se enseña en ninguna universidad del país. La importancia de aprender inglés descansa justamente en políticas de mercado; en términos generales no aprendemos inglés para leer a Shakespeare o a Faulkner, sino porque saber inglés es útil y necesario en el mundo de hoy. En cambio, aprender una de las lenguas originarias, puede que no. Este ejemplo, entonces, nos hace ver no solo en qué lógica se inscribe la educación formal de nuestros días, sino además bajo qué lógica operan las investigaciones ${ }^{3}$, elementos que pueden verse en la crítica que hace Santiago Castro-Gómez acerca de la idea de Habermas sobre su concepto de "colonización del mundo de la vida”. Dice el filósofo colombiano:

En primer lugar, el papel del conocimiento en la consolidación hegemónica de los sistemas abstractos y en la reproducción simbólica del mundo de la vida. Habermas sabe que la colonización de la vida cotidiana requiere necesariamente del concurso de la ciencia y la técnica, pero no muestra con claridad de qué manera el saber de los expertos contribuye (positiva o negativamente) a la formación de la vida social. En segundo lugar, Habermas no tematiza la vinculación de los sistemas expertos a relaciones geopolíticas de poder históricamente consolidadas, lo cual le lleva a ignorar un hecho fundamental: la "colonización del mundo de la vida" por sistemas desterritorializados es una herencia del colonialismo territorial de la modernidad. Esta herencia continúa reproduciéndose en el modo como la discursividad de las ciencias sociales y humanas se vincula a la producción de imágenes sobre el "Oriente", "África" o "Latinoamérica", administradas desde la racionalidad burocrática de universidades, instituciones culturales y centros de ayuda al desarrollo. (1998, p.122)

Esta racionalidad burocrática se convierte en un peligro y a la vez en una po-

3 No es el tema de este trabajo, pero, con todo, es bastante claro que acá entran a jugar un papel fundamental los recursos que invierten los Estados en investigaciones, donde comparativamente, no es mucho lo que se invierte en las investigaciones realizadas por las Ciencias Sociales. 
sibilidad para las investigaciones en Ciencias Sociales. Un peligro constante, en la medida en que las Ciencias Sociales están inscritas en el marco de esta racionalidad. No puede salirse de allí para elaborar sus teorías; es más, el peligro más radical consiste en configurar sus conocimientos según las exigencias de esta racionalidad. Por otra parte, es una posibilidad, en la medida en que, desde adentro puede hacer frente a ella, diríamos, en últimas, hacer crítica a estas formas burocratizadas del ser y del hacer. Así, con el primer ejemplo es posible evidenciar cómo socialmente se privilegian unas formas de saber sobre otras; con el segundo, cómo dentro de la lógica misma de las instituciones de conocimiento se legitima y se patrocina dicha jerarquización ${ }^{4}$.

La gran cuestión que se plantea de fondo para las Ciencias Sociales es, en esta medida, ¿qué sabemos acerca de lo social?, y más allá todavía, ¿con quiénes configuramos este conocimiento? Para los intereses de este texto, una buena oportunidad para averiguarlo es el espacio de conocimiento de lo social en lo que se refiere a los procesos de construcción de paz, en concreto, desde las organizaciones de víctimas, quienes a partir de sus maneras propias de ser, saber y de hacer, a la vez de construir paz extienden sus modos de comprender lo social, y cuyo ejercicio se muestra en tensión con una idea única y homogénea de construir paz, y así mismo única y homogénea de comprender lo social.

Para decirlo sintéticamente, el gran riesgo que se corre, no es solo el de la jerarquización del conocimiento, sino también el de su simplificación en la homogenización, similar a lo que sucede cuando hablamos de la paz, en vez de hablar de paces, en plural. Esto en la medida en que se comprende que, a pesar de que la idea de paz puede llegar a funcionar, entre encuentros y desencuentros, como un motor que moviliza todo tipo de acciones, variadas y diversas,

$4 \quad$ No sobra decir que con ambos ejemplos lo que se quiere dar a entender al lector es que la clasificación y jerarquización del conocimiento se da en un ejercicio discursivo de carácter múltiple; no es solo que haya algo como se señalaba en el viejo marxismo, algo como unas estructuras y unas super estructuras, sino que lo que tenemos es un mundo mucho más complejo en sentido dialéctico, donde, eso, sí se estratifican las formas de vida y, en esta línea, las formas de conocimiento. 
en contextos específicos se configuran no una, sino muchas modalidades de paz; entonces, de construir paces.

Para Hernández (2009) las investigaciones sobre las organizaciones sociales constructoras de paz en Colombia son relativamente recientes, pues su origen se remonta a los últimos años del siglo anterior. En sentido estricto esta fuente señala que los estudios de organizaciones constructoras de paz se originan en los años noventa. De este modo se destaca la presencia de las denominadas organizaciones de base social, las cuales emergen al lado de otras de origen oficial y con características sociales y de accionar particular.

\section{Estas organizaciones:}

Son escenarios de construcción de paz porque son realidades concretas, identificables en sectores poblacionales y en ámbitos geográficos de este país. No son utopías, no surgen de teorías académicas, ni son generadas desde afuera. Ellas tienen vida propia y responden a culturas, capacidades, necesidades y sueños específicos de los colectivos humanos que las integran. (Hernández, 2009, p.181)

El hecho de que emerjan desmarcadas en buena medida de teorías académicas y que no sean generadas desde fuera, sino como producto de necesidades y de asociaciones concretas, personificadas en colectivos y diversas formas de liderazgo, plantea una primera exigencia para los investigadores de dichas organizaciones: volver la mirada sobre estas maneras de ser, pensar y actuar, reconociendo allí los límites del saber formalizado entre las aulas y los espacios universitarios y aproximarse así a nuevas maneras de conocimiento, que pueden ir mucho más lejos de jerarquías burocráticas e intentos homogenizadores y homogenizantes 5 .

$5 \quad$ Podría decirse que en el fondo "todo esto tiene consecuencias importantes a la hora de pensar quiénes somos los latinoamericanos hoy en día, en tiempos de la globalización. Se trata, nuevamente, de la 
Por intentos homogenizadores se entiende aquí el tipo de quehacer que, desde el Estado, o de empresas privadas o desde las mismas universidades, busca configurar unos sujetos que sean determinados bajo ciertas normas aparentemente preestablecidas, como en el caso del ejemplo, patrocinar la idea de saber más de una lengua como positiva, pero al mismo tiempo, cerrar esta posibilidad a solo aprender una ("la más importante" para sobrevivir). Y por intentos homogenizantes se entienden las actividades sociales cotidianas que legitiman estas normas aparentemente consensuadas, como en el caso del hombre que niega su saber, buscando la aprobación de otros sobre cosas que realmente no le son importantes saber (como leer la hora en el reloj cuando realmente sus saberes son de otro tipo).

\section{Saber hacer las paces: oportunidades para abrir los conocimientos sobre lo social}

En este contexto es donde surgen las organizaciones de población víctima del conflicto armado como espacios para el restablecimiento de derechos y, en general, para reconstruir proyectos de vida individuales y colectivos desmembrados de manera profunda a raíz de la problemática de la cual se ha sido objeto. Las organizaciones de población víctima surgen entonces como dispositivos para aunar esfuerzos, en procura del logro de mejores condiciones de vida, situación que implica la puesta en marcha de procesos de interlocución ante la institucionalidad pública y privada local, nacional e internacional, es decir, implican una confrontación constante por devenir sujetos homogéneos; y, a su vez, para las Ciencias Sociales la apertura al diálogo y a la escucha de la polifonía de voces que de allí surgen.

Esta variedad étnica y cultural de las organizaciones hacen que, en medio de contextos hostiles, como cuando se pasa de habitar espacios rurales a habitar

eterna pregunta por la identidad, que ha movilizado gran parte del pensamiento filosófico en América Latina durante los últimos 200 años. Solo que la respuesta a esta pregunta ya no puede venir marcada por representaciones de tipo esencialista que establecen diferencias "orgánicas" entre los pueblos y las territorialidades, (Castro Gómez 2014, p.7). 
espacios urbanos, junto con prácticas de construcción de paz, se den ejercicios de resistencias y de sincretismos, de cara a lo que fueron y son las personas que integran las organizaciones en su ahora en la ciudad. Todo lo cual, no solo tiene que ver con la manera en la que se constituyen como organización, sino en las formas cómo desde sus saberes antiguos y nuevos comprenden el mundo. Elementos que sobrepasan cualquier forma tradicional de comprender en Ciencias Sociales el trabajo de campo. Como lo declara una líder afrodescendiente:

Los que hemos llegado acá que venimos desde un trabajo territorial, de un trabajo social, hemos venido a aportar a la ciudad y hemos venido también a aportar al afro aquí en la ciudad, también hemos venido a aportarle porque el afro se perdió en la ciudad, son personas comunes y corrientes, no tienen una etnia definida, no tienen una conciencia de ser pueblo, nosotros tenemos una conciencia de ser pueblo, como colectivo, como ciudadano. (Arias y Carrera, 2016, pp.59-60)

En esta medida es que las organizaciones de población víctima, desde sus prácticas y experiencias, han venido haciendo aportes importantes a la construcción de la paz, desde la reivindicación de sus derechos como ciudadanos y como víctimas del conflicto social y político en que se ha visto envuelta buena parte de la sociedad colombiana; dicha construcción se hace extensiva a través de los esfuerzos para propiciar con sus semejantes de las comunidades locales procesos comunitarios orientados hacia la búsqueda de mejores condiciones de vida, como también desde la reivindicación de la identidad colectiva. Lo mismo que desde los procesos de empoderamiento político, social y comunitario para hacer frente a las condiciones generalmente adversas de los sitios de llegada. Y esto solo lo pueden hacer en la medida en que ponen en diálogo sus saberes en el tiempo, a saber, en presente, en lo que respecta a su situación actual, en pasado, en lo que respecta a sus saberes tradicionales y, en futuro, en lo que respecta a la construcción del tipo de vida que desean configurar. "Aquí el diálogo de saberes se entiende como 'la relación mutuamente enriquecedora 
entre personas y culturas, puestas en colaboración por un deseo compartido'. La relación es construida por personas de culturas diversas vinculadas en el contexto del complejo de actividades/comportamientos/motivaciones denominado educación intercultural para el desarrollo sostenible" (Delgado y Ritz, 2016, p.15).

Igualmente se han venido desarrollando procesos de construcción de paz desde la reivindicación de los territorios y de las prácticas culturales, puestas en marcha por indígenas y afrodescendientes desde el destierro como un deber ético y político en consonancia con sus cosmovisiones ancestrales y ante la renuencia de desaparecer como grupos étnicos. Todo esto se consolida en saberes que al ser atendidos, discutidos y contemplados por las Ciencias Sociales, enriquecen sus formas epistemológicas y las abren más hacia un mundo complejo, que más de las veces se pierde o no se hace evidente en las aulas universitarias.

Estos procesos organizativos en su desarrollo y configuración deben aprender a trabajar con toda la carga social y cultural de sus protagonistas. Detrás de estos procesos hay prácticas, saberes y experiencias que marcan profundamente la vida de las organizaciones, y que son en última instancia, lo que las lleva a proceder y actuar de unas maneras específicas. Pese a los "dictámenes oficiales" que pugnan por homogenizar las dinámicas de las organizaciones, estas se rehúsan de manera abierta a tales determinaciones, poniendo en marcha procesos de resistencia que hablan de su historicidad y, en general, de toda la matriz cultural de quienes buscan dignificar sus condiciones de acuerdo con sus intereses, expectativas y necesidades. Lo más valioso, es que por extensión, sus búsquedas coinciden con la tenaz labor de dignificar la vida humana en su conjunto y de lo que entienden por buen vivir'6.

6 Concepto que varía de una comunidad a otra, así como de una organización a otra, pero que ciertamente tiene que ver con los elementos que se han venido mencionando acá, y que van desde la restitución de derechos mínimos hasta la realización de proyectos de vida en y como colectivos. De aquí la razón por la cual más que un desarrollo explícito, la categoría ha tenido uno implícito. 
En razón de lo anterior, cada vez cobra mayor validez la puesta en marcha de propuestas investigativas de orden teórico, epistemológico y práctico que permitan la interpretación e interlocución de la complejidad presente en las organizaciones de las poblaciones víctima constructoras de paz. En la actualidad existe una gran cantidad de trabajos que ayudan a la comprensión de lo que ha venido aconteciendo con las organizaciones en mención ${ }^{7}$, ameritan ser enriquecidos con otras propuestas investigativas que reivindiquen las voces y el lugar que les corresponde a sus integrantes como actores importantes en la construcción de conocimiento.

De hecho, una de las exigencias radica hoy en día en trascender los espacios de visibilización a otras instancias; en los trabajos mencionados, aparece si la puesta en marcha de la comprensión de los saberes y prácticas de las organizaciones, como modos de resistencia, generan una deuda con el reconocimiento completo de estas en el sentido de que se integren dichas cosmovisiones y comprensiones del mundo como interlocutores válidos a nuestras maneras propias de aproximarnos a la cuestión siempre problemática de lo real. De otro modo, estos valiosos espacios de visibilización terminarán por convertirse en espacios conmemorativos de aspectos "exóticos" (ajenos) a nuestras formas de vida, atravesadas desde lo académico por el modelo burocrático imperante y toda su estructura social. De modo tal que una visibilización más crítica de las organizaciones ha de ayudar a generar espacios de reflexión en al menos tres niveles:

1. Para las organizaciones mismas, con el fin de que el diálogo de saberes conlleve un ejercicio de auto-comprensión, en el que estas puedan verse a sí

7 Los ejemplos en esta línea son innumerables y ya hay una buena cantidad bibliográfica sobre experiencias de paz. Recomiendo, en esta línea, algunos trabajos como el libro de la profesora Esperanza Hernández, Intervenir antes que anochezca (2012); el libro de la profesora Esperanza Gómez Hernández, Diálogo de saberes e interculturalidad (2015), donde además aparece desarrollada a profundidad la compleja categoría de "diálogo de saberes"; y el trabajo de los profesores Luis Alberto Arias y Patricia Carrera, Las organizaciones indígenas y afrodescendientes desplazadas en Bogotá y sus resignificaciones culturales (2016). 
mismas con mayor distancia, y ello pueda fortalecerlas desde lo que logran llevar a cabo exitosamente y aquello que puede convertirse en aprendizajes.

2. Para el mundo académico, con el fin de que se abra el horizonte de comprensión de lo social y los aspectos que tocan a la configuración de procesos que enseñan nuevas formas de entender el mundo.

3. Para la sociedad en su sentido más amplio, con el fin de propiciar escenarios para nuevos diálogos, en donde intereses comunes confluyan en saberes también comunes. Principalmente en lo que refiere ese gran proyecto de dignificar la vida humana.

De hecho, vale la pena hacer un último ejemplo, para ver cómo, en el marco de las construcciones de paz de estas organizaciones, cada vez nos podemos aproximar más a la superación de la categoría cerrada de "víctimas" que, aunque funcional en términos jurídicos, es insuficiente en contextos de construcción de paces. En el marco de los ejercicios de reconciliación con la comunidad no-víctima, que realizan miembros de la Fundación Ágape por Colombia aparecen frente a un tablero dos mujeres: una a la derecha y otra a la izquierda. Ambas comienzan a dibujar: la de la izquierda dibuja tres ramas secas, la una sobre la otra en un espacio vertical; la de la derecha, dibuja una semilla, debajo un árbol que comienza a crecer y debajo de este, un árbol con frutos florecidos. Luego, miran fijamente al público y dice primero la de la izquierda: "yo era víctima; sigo siendo víctima"; la de la derecha: "yo era víctima, ahora soy actor de paz". Esto para decir que en una categoría cerrada como lo es la de "víctima", dentro de las mismas organizaciones se expande dentro de nuevas formas de comprender y configurar lo social, que rompen justamente con los cuadros de lo homogenizador y lo homogenizante.

8 La cual tiene cerca de 14 años de experiencia en el trabajo con víctimas, victimarios, jóvenes desvinculados y adultos desmovilizados, en ejercicios de reconciliación en cuyos conocimientos, es posible decir que está el saber del perdón, del respeto por el otro, de la capacidad de una comunicación asertiva, etc.

9 Categoría que merece un trabajo de mayor profundidad, más allá de la simple mención que ofrece el presente trabajo. 
En esta línea, tal y como lo plantea Herrera (2010), desde la segunda mitad del siglo anterior, las Ciencias Sociales vienen experimentando un proceso de resignificación de sus fundamentos básicos, situación que las lleva a distanciarse cada vez más de su supuesta neutralidad valorativa, lo mismo que de las pretensiones de objetividad y de la separación sujeto-objeto en el proceso de conocimiento, la cual, entre otras cosas en buena medida fue cómplice de esa invención-dominación de lo "otro" de la que habla, por ejemplo, Edward Said en un texto como Orientalismo, cuando afirma que una cierta voluntad de comprender aquello que era distinto a la cultura occidental de la que emergieron la mayoría de ciencias sociales coincidió con "controlar, manipular e incorporar lo que manifiestamente es un mundo diferente" (2002, p.34).

En su lugar, en cambio, viene tomando fuerza la filosofía hermenéutica como fundamento teórico y epistemológico que ofrece nuevas posibilidades de acercamiento, comprensión e interpretación de las comunidades locales. Por su parte, Molano (2007) reivindica el estudio de la sabiduría y los saberes como componentes básicos de la dimensión humana, entendiendo por estos:

(...) el pensamiento ancestral sustentado en la sabiduría y constituido en cosmovisiones que interpretan el universo, la tierra, el origen humano y la bondad de la tierra mediante una serie de mitos y expresiones simbólicas de gran riqueza y sentido. La sabiduría y los saberes están íntimamente relacionados con la cultura popular y con la razón de ser de los pueblos. (Molano, 2007, p.289)

Santos (2010) considera fundamental para las Ciencias Sociales la reinvención de categorías de acercamiento a la realidad acorde con las características de estas. Señala cómo buena parte del arsenal teórico de estas ciencias se configura en algunos países de Europa hacia el siglo XIX, en coherencia con sus condiciones históricas, sociales y culturales, las cuales resultan inadecuadas para 
comprender las realidades de los países como América Latina o del contexto africano.

Para el caso concreto en el que se inscribe este texto, aparece toda una serie de exigencias para las Ciencias Sociales dadas desde los procesos organizativos y de inserción en las comunidades locales, cuya construcción de saberes es la apertura de saberes otros (no formalizados) del mundo, de sí mismos y del espectro social, que se desmarcan y se resisten a los saberes construidos de forma tradicional durante el siglo XIX y a lo largo del XX (Wallerstein 2007). En concreto, los saberes que allí aparecen tienen que ver con movimientos de construcción efectiva de las paces, basados en una comprensión de lo social, acerca del cual no solamente el investigador ha de tomar nota, sino que ha de dialogar con y ha de participar de dichos saberes, deshomogenizando así la historia, los modos en los que nos comprendemos políticamente y en que venimos pensando a los hombres y mujeres de hoy.

\section{Conclusiones}

Es claro que en las dinámicas sociales del mundo actual se corre el riesgo, tanto epistemológico como ético, de devenir sujetos homogenizados por las diversas formas de institucionalización y jerarquización de nustras prácticas y saberes, tanto por dentro como por fuera de las universidades y de su quehacer investigativo. Sin embargo, el acercamiento a las organizaciones de población víctima que trabajan por la paz, permite confrontar los conocimientos que han acumulado las Ciencias Sociales con la multiplicidad de saberes desde los cuales los sujetos que integran dichas organizaciones han venido aportando desde su ser, hacer y saber.

En esta línea, la implicación de la apertura a los diálogos de saberes es ella misma una comprensión más amplia acerca de lo social. Esto tiene que ver con el hecho de que las investigaciones hacen pensar constantemente en la forma en que históricamente se ha venido haciendo ciencia social, el sentido en el que se 
configuran sus categorías y las maneras de pensar en los sujetos investigadores y los sujetos mismos de conocimiento.

Por último, las reconfiguraciones que recientemente han experimentado las ciencias sociales, a la vez que permiten el reconocimiento de saberes históricamente excluidos, abren posibilidades para nuevas reconstrucciones al interior de dichas ciencias. Como, para el caso, el ejemplo en el que asumir la relación con las organizaciones implica generar una reflexión amplia, donde además de visibilizar procesos, hay una apropiación de los mismos, más allá de una investigación indiferente a los espacios propios de la vida cotidiana.

\section{Referencia Bibliográficas}

\section{Libros}

ACODESI (2003). Hacia una educación para la paz. Bogotá: Kimpres.

Arias, L. \& Carrera, P. (2016). Las organizaciones indígenas y afrodescendientes desplazadas en Bogotá y sus resignificaciones culturales. Bogotá: Fundación Universitaria Unimonserrate.

Bloomfield, D. (2003). Recontiliation After Violent Confict. International Institute for Democracy and Electoral Assistance.

Delgado, F. \& Ritz, S. (2016). Ciencias, diálogo de saberes y transdisciplinariedad. La Paz: Agruco.

Castro-Gómez, S. (1998). Teorías sin disciplina-(lationamericanismo, poscolonialidad y globalización en debate). CLACSO, Consejo Latinoamericano de Ciencias Sociales, Buenos Aires, Argentina. Julio de 2000.

Espitia, C. Comp. (2015). En la ruta hacia la paz. Bogotá: Centro de Memoria Histórica.

Galtung, J. (1985). Sobre la paz. Barcelona; Rapoport.

Gaultung, J. (1996). Peace by paceful means/peace and conflicts, development and civilization. Oslo: Prio.

Gómez, E. (2015). Diálogo de Saberes e Interculturalidad. Medellín: Pulso y letra. 
Hayner, P. (2011). Unspeakable Truths-Transitional Justice and the Challenge of Truth Commissions. New York: Routegle.

Hernández, E. (2012). Intervenir antes que anochezca. Bucaramanga: Universidad Autónoma de Bucaramanga.

Herrera, J. (2010). La comprensión de lo social. Horizonte hermenéutico de las Ciencias Sociales. Bogotá: Fundación Centro Internacional de Educación y Desarrollo (CINDE).

Matyòk, T., Senehi, J., Byrne, S. (2011). Critical Issues in Peace and Conflict Studies. New York: Lexington Books.

Molano, A. (2011). Fragmentos de la Historia del conflicto armado (1920-2010). PDF. Recuperado de: http://www.altocomisionadoparalapaz.gov.co/ mesadeconversaciones/PDF/fragmentos-de-la-historia-del-conflicto-armado-1920-2010-1447167631-1460380435.pdf.

Muñoz, F. (2005). La paz imperfecta ante un universo en conflicto. PDF. Recuperado de: http://www.ugr.es/ eirene/eirene/Imperfecta.pdf

Pizarro, E. Comp. (2014). Contribución al entendimiento del conflicto armado en Colombia. Comisión histórica del conflicto y sus víctimas. Bogotá: Desde Abajo.

Reyes, M. (1991). La razón de los vencidos. Madrid: Antrophos.

Said, E. (2002). Orientalismo. Barcelona: De bolsillo.

Santos, B. (2010). Decolonizar el saber, reinventar el poder. Montevideo: Trilce.

Wallerstein, I. (2007). Análisis de sistemas-mundo, una introducción. México: Siglo XXI.

\section{Artículos}

Cabezudo, A. (2012). "Educación para la paz: una construcción de la memoria, la verdad y La justicia. Desafío pedagógico de nuestro tiempo en América Latina”. En: Ciencias Sociales Unisinos, 48, 139-145.

Cerdas, E. (2015). Desafíos de la educación para la paz, hacia la costrucción de una cultura de paz. Educare, 19(2), 135-154.

Dueñas, M., Rodríguez, M. (2002). "Educar para la paz enseñando historia”. 
Investigación y Desarrollo, 10, 40-53.

Hernández, E. (2009). Paces desde abajo en Colombia. Revista Reflexión política (22), 176- 186.

Fernández, A. y López, M. (2014) "Educar para la paz. Necesidad de un cambio epistemológico". Convergencia. Revista de Ciencias Sociales, 21(64)117142.

Manzano, C. (2014). Víctimas, victimarios: El papel de las universidades en la construcción de cátedras de paz. Jurídicas CUC, 10(1), 27 - 42.

Martínez, V. (2000). "Saber hacer las paces: Epistemología de los estudios para la paz". Convergencia. Revista de Ciencias Sociales, 23, 49-96.

Massò, E. (2008). "El desafío de la paz como quehacer humano: retos (antropológicos, sociales y políticos) de culturas y pueblos. Derechos humanos, cultura(s) de paz”. Límite. 3, 31-52.

Nasi, C., Rettberg, A. (2005). "Los estudios sobre conflicto armado y paz: un campo en evolución permanente". Colombia Internacional. 62, 64-85.

Soriano, C. (2010). La esclavitud en la obra de Acosta Saignes: estudios subalternos y el problema de construir las historias del otro. En Revista Venezolana de Economía y Ciencias Sociales, 16(1), 145-156.

Villar, G., Maldonado, A. (2013). "Los medios de comunicación y su injerencia en la costrucción de cultura de paz o violencia. Una reflexión desde los estudios para la paz". Ramxihai, 9, 47-75. 